\title{
Resíduos de glifosato e ácido aminometilfosfônico e teores de isoflavonas em soja BRS 244 RR e BRS 154
}

\author{
Residues of glyphosate and aminomethylphosphonic acid and \\ levels of isoflavones in BRS $244 R R$ and BRS 154 soybean
}

\author{
Giani Mariza Bärwald BOHM ${ }^{1 \star}$, Maria Inés GENOVESE², Gustavo PIGOSSO², \\ Daniel TRICHEZ ${ }^{3}$, Cesar Valmor ROMBALDI ${ }^{4}$
}

\begin{abstract}
Resumo
A principal forma de controle das plantas daninhas durante o cultivo de soja geneticamente modificada $\left(\mathrm{GM}_{\mathrm{RR}}\right) \mathrm{BRS}_{244} \mathrm{RR}$ é o uso de

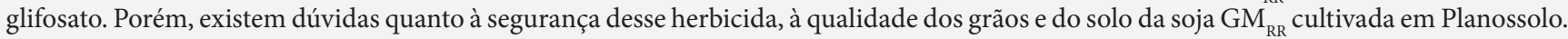
Resíduos da molécula do glifosato e do metabólito ácido aminometilfosfônico (AMPA) podem estar presentes nos grãos, bem como, podem afetar a concentração de isoflavonas. Por isso, avaliaram-se as sojas BRS 244 RR e BRS 154 cultivadas nos seguintes tratamentos: T1 - soja BRS 244 RR, sem aplicação de herbicida, com capina manual aos 28 dias após o plantio (dap); T2 - soja BRS 154 sem aplicação de herbicida, com capina manual também aos 28 dap; T3 - soja BRS 244 RR com uma aplicação de glifosato a 960 g ia ha ${ }^{-1}$ aos 28 dap; T4 - soja BRS 244 RR com duas aplicações de glifosato a $960 \mathrm{~g}_{\text {ia ha }}{ }^{-1}$ aos 28 e 56 dap; T5 - soja BRS 244 RR com uma aplicação de herbicida imazetapir a $100 \mathrm{~g}_{\text {ia ha }}{ }^{-1}$ aos 28 dap; T6 - soja BRS 154 com uma aplicação de herbicida imazetapir a $100 \mathrm{~g}^{\text {ia ha }} \mathrm{h}^{-1}$ aos 28 dap. Verificou-se que a aplicação de glifosato no controle de plantas daninhas resultou em teores elevados de glifosato e ácido aminometilfosfônico no solo. Nos grãos, o teor de isoflavonas não parece ser significativamente afetado pela aplicação de glifosato, mas os resíduos desse herbicida foram superiores ao permitido pela legislação vigente, que é de $10 \mathrm{mg} \cdot \mathrm{kg}^{-1}$.
\end{abstract}

Palavras-chave: herbicida; AMPA; soja transgênica.

\begin{abstract}
The use of Glyphosate is the best way to control weed growing when cultivating genetically modified soybean (GMRR) BRS 244 RR. However, there have been doubts about the safety of this herbicide use concerning its effects on the quality of grains and on the soil of Albaqualf cultivated GMRR soybean. Glyphosate and the metabolite aminomethylphosphonic acid (AMPA) residues can be present in the grains and affect the isoflavones concentration. Therefore, BRS 244 RR and BRS 154 soybeans with the following cultivated treatments were evaluated: T1 - soybean BRS 244 RR, without herbicide and hand-weeded at 28 days after planting (dap); T2 - soybean BRS 154, without herbicide and hand-weeded at 28 dap; T3 - soybean BRS 244 RR with one application of $960 \mathrm{~g}$ ai ha ${ }^{-1}$ of glyphosate at 28 dap; T4 - soybean BRS 244 RR, with two applications of $960 \mathrm{~g}$ ai ha $\mathrm{a}^{-1}$ of glyphosate at 28 and $56 \mathrm{dap}$; T5 - soybean BRS $244 \mathrm{RR}$, with one application of $100 \mathrm{~g}$ ai ha $\mathrm{H}^{-1}$ of imazethapyr at $28 \mathrm{dap}$; and T6 - soybean BRS 154 with one application of $100 \mathrm{~g} \mathrm{ai} \mathrm{ha}^{-1}$ of imazethapyr at $28 \mathrm{dap}$. It was verified that the glyphosate application for weed control resulted in high levels of glyphosate and aminomethylphosphonic acid on the soil. The levels of isoflavone in the grains apparently were not affected by the glyphosate application, but the herbicide residues were higher than the current amount allowed by the legislation $\left(10 \mathrm{mg} \cdot \mathrm{kg}^{-1}\right)$. Keywords: herbicide; AMPA; transgenic soybean.
\end{abstract}

\section{Introdução}

A planta geneticamente modificada mais cultivada no Brasil é a soja [Glycine max (L.) Merr.] resistente ao herbicida glifosato, com 11,5 milhões de hectares cultivados (ISAAA, 2006). A soja geneticamente modificada resistente ao glifosato $\left(\mathrm{GM}_{\mathrm{RR}}\right)$ foi obtida pela introdução, juntamente com a região t-DNA e o gene marcador de seleção, de gene correspondente à enzima 5-enolpiruvilchiquimato-3-fosfato sintase (EPSPS, E.C. 2.5.1.19, CP4), enzima da via de chiquimato, resistente ao glifosato, mantendo ativa a via biossintética de aminoácidos aromáticos (BUSSE et al., 2001). O glifosato [N-(fosfonometil) glicina] age sobre a enzima EPSPS inibindo a via de síntese dos aminoácidos aromáticos essenciais, fenilalanina, triptofano e tirosina, os quais são precursores de outros produtos, como lignina, alcalóides, flavonóides e ácidos benzóicos (AMARANTE; SANTOS, 2002). A priori, a soja $\mathrm{GM}_{\mathrm{RR}}$ é tolerante ao glifosato por possuir uma isoforma da EPSPS resistente a essa molécula. Porém, é sabido que o glifosato será absorvido e metabolizado pela planta podendo alterar o metabolismo secundário, uma vez 
que a enzima EPSPS endógena se mantém inalterada (REDDY et al., 2000).

A recomendação técnica prescrita no registro do produto comercial que contém glifosato para aplicação pós-emergente de soja $\mathrm{GM}_{\mathrm{RR}}$, junto ao Ministério da Agricultura, é de 1 a $5 \mathrm{~L} \mathrm{ha}^{-1}$

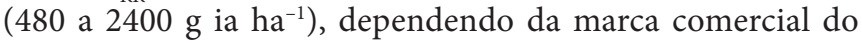
produto. O período de carência para utilização do glifosato é de 56 dias antes da colheita. Essa orientação parte do pressuposto de que respeitadas as dosagens e prazo de carência, serão mantidos os limites de resíduo no grão abaixo do parâmetro preconizado pela legislação vigente que é de $10 \mathrm{mg} \cdot \mathrm{kg}^{-1}$. Ressalta-se, ainda, que até 1994, o limite máximo permitido de glifosato nos grãos era de $0,2 \mathrm{mg} \cdot \mathrm{kg}^{-1} \mathrm{e}$, a partir daí, aumentou-se em 50 vezes esse limite para a soja $\mathrm{GM}_{\mathrm{RR}}$, passando para $10 \mathrm{mg} \cdot \mathrm{kg}^{-1}$ (ANVISA, 2007).

Embora o Brasil seja o $3^{\circ}$ maior produtor mundial de soja $\mathrm{GM}_{\mathrm{RR}}$, somente superado pelos EUA e Argentina, poucos trabalhos têm sido conduzidos no País com o intuito de avaliar, em ensaios de campo, o impacto dessa tecnologia sobre a qualidade e segurança dos grãos, num mesmo modelo experimental, em áreas de Planossolo, que constitui a base experimental deste trabalho.

Alguns autores como Padgette et al. (1995), Taylor et al. (1999), Duke et al. (2003), Reddy et al. (2004) e McCann et al. (2005) estudaram o efeito da aplicação de glifosato no manejo de soja $\mathrm{GM}_{\mathrm{RR}}$ e na composição básica dos grãos. Inicialmente, Padgette et al. (1995) avaliaram a expressão do gene CP4 EPSPS em soja resistente a glifosato na presença e ausência desse herbicida e verificaram um acúmulo similar da proteína CP4 EPSPS em ambas as condições. Na seqüência, Taylor et al. (1999) e McCann et al. (2005), ao compararem variedades comerciais de soja $\mathrm{GM}_{\mathrm{RR}}$ com as convencionais, verificaram que a transformação genética não interfere nos teores de proteínas, carboidratos, gorduras, aminoácidos e isoflavonas. Mas, no que concerne a resíduos, Duke et al. (2003), analisando o manejo da soja $\mathrm{GM}_{\mathrm{RR}}$ tratada com glifosato sob diferentes dosagens, detectaram elevados teores de AMPA nos grãos, porém, à semelhança de Taylor et al. (1999) e McCann et al. (2005), não observaram efeito da aplicação do herbicida sobre os teores de chiquimato e de isoflavonas. Reddy et al. (2004) observaram efeitos tóxicos para a planta e redução dos teores de clorofilas quando o glifosato foi aplicado na dosagem $13.440 \mathrm{~g}$ ia ha ${ }^{-1}$, afetando a composição dos grãos.

Outro aspecto relacionado com o efeito do manejo da soja $\mathrm{GM}_{\mathrm{RR}}$ é a presença de resíduo do herbicida no solo. Ginsing et al. (2004) investigaram, em condições de laboratório, a mineralização do glifosato e a adsorção do metabólito AMPA em cinco tipos de solos coletados na Dinamarca, nos quais observaram que o principal metabolismo de bioconversão de glifosato no solo está associado à mineralização, especialmente, por Pseudomonas spp. De forma semelhante, Araújo et al. (2003) detectaram incremento de 10 a $15 \%$ na liberação de $\mathrm{CO}_{2}$ em solos nos quais houve aplicação de glifosato na dosagem de $4320 \mathrm{~g}_{\text {ia }} \mathrm{ha}^{-1}$, sugerindo que a microbiota do solo é capaz de metabolizar o glifosato como uma fonte de carbono, em ensaios in vitro. Outro fato relatado nesse trabalho foi a detecção de resíduo de glifosato e AMPA no solo, em maiores concentra- ções em áreas nas quais se realizaram aplicações de glifosato em anos sucessivos.

No entanto, não há dados publicados sobre as respostas à aplicação de glifosato em soja $\mathrm{GM}_{\mathrm{RR}}$ cultivada em Planossolos, amplamente conhecidos pela alta concentração de argila e permeabilidade lenta. Além disso, a maioria dos trabalhos que abordam essa temática, ou estruturaram os experimentos in vitro (BUSSE et al., 2001; ARAÚJO et al., 2003), ou em casa de vegetação (REDDY et al., 2004), ou desenvolvidas no campo, (ELMORE et al., 2001; DUKE et al., 2003). Nesse contexto, buscou-se avaliar o efeito da aplicação do glifosato para o controle de plantas daninhas, nos resíduos dessa molécula e de AMPA no solo e nos grãos, bem como nos teores de isoflavonas nos grãos. A hipótese do trabalho é que a aplicação de glifosato no controle de plantas daninhas no cultivo de soja $\mathrm{GM}_{\mathrm{RR}}$, cultivada em áreas de Planossolo, resulta em resíduos de glifosato e AMPA nos grãos e solo, bem como pode afetar a síntese e acúmulo de compostos relacionados com o metabolismo secundário da planta, como é o caso de isoflavonas.

\section{Material e métodos}

\subsection{Material vegetal}

O experimento foi instalado, na safra 2005/2006, em campo experimental do Centro Agropecuário da Palma (CAP), da Universidade Federal de Pelotas, localizado no município do Capão do Leão, Rio Grande do Sul, Brasil. O solo da área experimental é classificado como Planossolo Háplico Eutrófico Solódico, tendo como origem sedimentos derivados de granito (EMBRAPA, 2006). Como material vegetal, foram utilizadas sementes de soja $\mathrm{GM}_{\mathrm{RR}}$ das cultivares BRS 244 RR e BRS 154 fornecidas pela EmbrapaTrigo (Passo Fundo-RS).

\subsection{Delineamento experimental e tratamentos}

A área experimental foi selecionada considerando-se o histórico (nunca houve plantio de soja) e a homogeneidade topográfica (plana). As principais características físico-químicas do solo da área experimental estão apresentadas na Tabela 1.

As parcelas experimentais constaram de áreas individuais com $4 \times 5 \mathrm{~m}$, aleatoriamente distribuídas em um delineamento inteiramente casualizado dentro do campo experimental, com 4 repetições por tratamento.

O plantio foi realizado durante a primeira quinzena de dezembro de 2005, com sementes previamente tratadas com fungicida Derosal Plus ${ }^{\circledR}$ e inoculadas com Bradyrhizobium japonicum Semia 5079 e Bradyrhizobium elkanii Semia 587.

Os tratamentos aplicados para testar a hipótese foram:

T1 - soja BRS 244 RR sem aplicação de herbicida, com capina manual aos 28 dias após o plantio (dap);

T2 - soja BRS 154 sem aplicação de herbicida, com capina manual aos 28 dap;

T3 - soja BRS 244 RR com uma aplicação de glifosato a $960 \mathrm{~g}^{\text {ia ha }}{ }^{-1}$, aos 28 dap; 
Tabela 1. Características físico-químicas do solo na área experimental do Centro Agropecuário da Palma, UFPEL, Pelotas, RS.

\begin{tabular}{lc}
\hline \multicolumn{1}{c}{ Variável } & Valor \\
\hline Argila $\left(\mathrm{g}_{\mathrm{kg}} \mathrm{kg}^{-1}\right)$ & 16 \\
$\mathrm{pH}$ & 4,5 \\
Índice SMP & 5,7 \\
Matéria orgânica (\%) & 2,6 \\
Fósforo $\left(\mathrm{mg} \mathrm{dm}^{-3}\right)$ & 4,9 \\
Potássio $\left(\mathrm{mg} \mathrm{dm}^{-3}\right)$ & 27 \\
Cálcio $\left(\mathrm{cmol}_{\mathrm{c}} \mathrm{dm}^{-3}\right)$ & 1,2 \\
Magnésio $\left(\mathrm{cmol}_{\mathrm{c}} \mathrm{dm}^{-3}\right)$ & 1 \\
Alumínio $\left(\mathrm{cmol}_{\mathrm{c}} \mathrm{dm}^{-3}\right)$ & 1,4 \\
Cobre $\left(\mathrm{mg} \mathrm{dm}^{-3}\right)$ & 1,4 \\
Ferro $\left(\mathrm{g} \mathrm{dm}^{-3}\right)$ & 10 \\
Manganês $\left(\mathrm{mg} \mathrm{dm}^{-3}\right)$ & 51 \\
Zinco $\left(\mathrm{mg} \mathrm{dm}^{-3}\right)$ & 1,3 \\
Sódio $\left(\mathrm{mg} \mathrm{dm}^{-3}\right)$ & 48 \\
\hline
\end{tabular}

T4 - soja BRS 244 RR com duas aplicações de glifosato a $960 \mathrm{~g}^{\text {ia ha }}{ }^{-1}$, aos 28 e 56 dap;

T5 - soja BRS 244 RR com uma aplicação de herbicida Imazetapir a $100 \mathrm{~g}$ ia ha ${ }^{-1}$, aos 28 dap; e

T6 - soja BRS 154 com uma aplicação de herbicida Imazetapir a $100 \mathrm{~g}_{\text {ia ha }}^{-1}$, aos $28 \mathrm{dap}$.

\subsection{Avaliações}

Aos 90 dias após a emergência da planta, correspondendo ao estádio R6 do desenvolvimento da soja, foram retiradas, com auxílio do trado de rosca, amostras de solo na profundidade de 0-20 cm de cada unidade experimental para análise de resíduo de glifosato e AMPA. Para análise de resíduo de glifosato e AMPA, bem como de isoflavonas em grãos, as amostras foram coletadas por ocasião da colheita quando apresentavam, em média, 21\% de umidade. Os grãos foram secos até aproximadamente $12 \%$ de umidade em estufa com circulação forçada de ar a $60 \pm 5^{\circ} \mathrm{C}$.

A colheita foi realizada na primeira quinzena de maio de 2006. Desse modo, os tratamentos realizados em 28 e 56 dap, correspondem a 120 e 90 dias antes da colheita, respectivamente, atendendo ao período de carência exigido para a aplicação do glifosato.

\subsection{Detecção e quantificação de resíduo de glifosato e AMPA no solo e nos grãos}

O método adotado segue exatamente o protocolo escrito por Veiga et al. (2001). Para análise de resíduo da molécula de glifosato e AMPA, amostras do solo foram secas a $40{ }^{\circ} \mathrm{C}$ e, em seguida, peneiradas em peneiras de $2 \mathrm{~mm}$. O glifosato e AMPA foram extraídos com solução de dihidroxifosfato de potássio. Cinco gramas da amostra foram mantidos em agitação durante

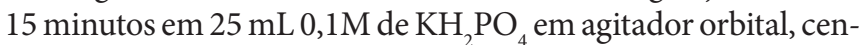
trifugado por 10 minutos a $2500 \mathrm{~g}$ e filtrado em filtro Whatman ${ }^{\oplus}$ $\mathrm{n}^{\circ} 2$. A extração foi repetida duas vezes, obtendo-se $75 \mathrm{~mL}$ de extrato de cada amostra. Os extratos foram concentrados a baixas temperaturas (freeze-dried $\mathrm{Vac}^{\circledast}$ ) e dissolvidos em água Milli-Q ${ }^{\odot}$ num volume final de $10 \mathrm{~mL}$. Esses extratos foram filtrados através de membrana de Millipore ${ }^{\bowtie} 0,45 \mu \mathrm{m}$, e armazenados a $-20^{\circ} \mathrm{C}$ até análise por CLAE (cromatografia líquida de alta eficiência). Para realizar a derivação, a $0,1 \mathrm{~mL}$ de extrato foram adicionados $0,9 \mathrm{~mL}$ de tampão borato 0,025 $\mathrm{M}(\mathrm{pH} 9,0)$, $0,9 \mathrm{~mL}$ de acetona e $0,1 \mathrm{~mL}$ 9-fluorenylmethyl chloroformate (FMOC). A amostra foi agitada por 5 minutos, seguidos de 20 minutos de repouso, após os quais se realizaram três lavagens com éter etílico.

A separação de glifosato e AMPA foi realizada em equipamento de CLAE composto por injetor de $50 \mu$ L Loop Rheodyne ${ }^{\varpi}$, coluna de troca aniônica $\mathrm{C}_{18}$ de $150 \times 2.0 \mathrm{~mm}$ com partícula de $5 \mu \mathrm{m}$ (Supelco, Bellefonte, PA, USA) e detector espectrofluorométrico Shimadzu ${ }^{\oplus}$. A fase móvel consistiu de água padrão CL (Cromatografia líquida) pH 2.5 (ajustado com acido fórmico) na fase 1, e uma mistura aquosa de $5 \mathrm{mM}$ de acetato de amônia (pH 4.8), água padrão CL e acetonitrila na fase 2. Os padrões analíticos de 9-fluorenylmethyl chloroformate (FMOC), glifosato e AMPA foram obtidos da Sigma-Aldrigh ${ }^{\circledR}$. A acetona, éter etílico e acetonitrila foram obtidos da $\mathrm{Merck}^{\circledast}$.

Para a análise de resíduo de glifosato e AMPA nos grãos, o método foi similar, excetuando-se o preparo da amostra que consistiu em utilizar $1 \mathrm{~g}$ de grãos moídos, submetidos à extração com $15 \mathrm{~mL}$ de água Milli- $\mathrm{Q}^{\circledR}$, mantidos sob agitação por 30 minutos, seguidos por sonicação por 20 minutos e centrifugação a 2000 g a $20^{\circ} \mathrm{C}$ por 20 minutos. Em seguida, $4 \mathrm{~mL}$ do sobrenadante foram retirados e filtrados em membrana Millipore ${ }^{\circledast} 0,45 \mu \mathrm{m}$. Ao pellet, foram adicionados $5 \mathrm{~mL}$ de água e repetiram-se a sonicação, centrifugação e filtração. A partir daí seguiram-se os mesmos procedimentos de derivação e quantificação descritos por Veiga et al. (2001). Os limites de quantificação foram de $0,04\left(\mathrm{~g} . \mathrm{kg}^{-1}\right)$ para a molécula de glifosato, $0,60\left(\mathrm{~g} \cdot \mathrm{kg}^{-1}\right)$ para o AMPA e $0,10\left(\mathrm{~g} \cdot \mathrm{kg}^{-1}\right)$ para imazetapir.

\subsection{Extração e quantificação de isoflavonas}

Para a análise de isoflavonas, os grãos de soja foram moídos em moinho Janke \& Kunkel A-10 (Wilmington, USA) com peneira de $0,25 \mathrm{~mm}$. A extração das isoflavonas foi realizada com agitador mecânico e barra magnética por 2 horas a $4{ }^{\circ} \mathrm{C}$, na proporção de 1:20 (m/v), com metanol 80\% (GENOVESE; LAJOLO, 2001). Os extratos foram filtrados utilizando-se papel de filtro Whatman $\mathrm{n}^{\circ} 6$ e submetidos à rotaevaporação (Rotavapor ${ }^{\circledast} \mathrm{RE}$ 120 - Büchi, Flawil, Suíça) até atingir o volume de $2 \mathrm{~mL}$. A seguir, completou-se o volume para $5 \mathrm{~mL}$ em balão volumétrico com metanol (grau CLAE). As amostras foram filtradas utilizandose filtros de polietileno com membrana PTFE (Millipore Ltd., Bedford, EUA) de 0,22 $\mu \mathrm{m}$ de poro para posterior análise por CLAE. As extrações foram realizadas em triplicata.

A separação das isoflavonas foi realizada em coluna $C_{18}$ Nova-pak $4 \mu \mathrm{m}$ (Waters, Milford, EUA) de acordo com $\mathrm{o}$ método proposto por Song et al. (1998). O cromatógrafo líquido utilizado foi o da Hewlett Packard (Palo Alto, EUA) série 1100, equipado com Detector com Arranjo de Diodo (DAD). Os padrões de daidzeína e genisteína foram obtidos da Sigma 
Chemicals Co. (St. Louis, E.U.A.), daidzina e genistina foram obtidos da Apin Chemicals Ltd. (Abingdon, Reino Unido), glicitina e gliciteína foram obtidos da Fujicco Co. Ltd. (Kyoto, Japão), acetildaidzina, acetilgenistina, acetilglicitina, malonildaidzina, malonilgenistina e malonilglicitina foram obtidos da LC Laboratories (Woburn, E.U.A.). A identificação foi feita a partir dos tempos de retenção e dos espectros. As amostras foram injetadas em duplicatas. Os resultados foram expressos como mg de isoflavona por $100 \mathrm{~g}$ de amostra (b.u.), após normalização das diferenças de peso molecular das amostras glicosiladas, feita multiplicando-se a massa de cada derivado pela razão entre o peso molecular da respectiva aglicona e o peso molecular da forma glicosilada, conforme Song et al. (1998).

\subsection{Análise estatística}

Os dados foram submetidos à análise de variância, e à comparação de médias pelo método LSD, utilizando-se o programa Statistix $8.0^{\circledR}$.

\section{Resultados e discussão}

A aplicação de glifosato na soja $\mathrm{GM}_{\mathrm{RR}}$ resultou na presença de resíduos no solo e nos grãos (Tabela 2). O que era esperado com base nos trabalhos prévios de Veiga et al. (2001), Araújo et al. (2003) e Duke et al. (2003), embora os valores tenham sido distintos entre os trabalhos realizados. Porém, de modo geral, os valores de resíduos detectados neste trabalho foram superiores aos citados por estes autores. Mais detalhadamente, foi verificado que a realização de uma (T3) ou duas (T4) aplicações de glifosato, na dosagem de $960 \mathrm{~g}^{\text {ia ha }} \mathrm{ha}^{-1}$, resultou em resíduos de 0,40 e 0,30 mg. $\mathrm{kg}^{-1}$ de solo, não havendo diferença significativa entre os tratamentos $(\mathrm{p} \leq 0,05)$. O resíduo de AMPA foi significativamente superior $(\mathrm{p} \leq 0,05)$ no solo de parcelas que receberam duas aplicações de glifosato (T4), passando de 1,03 mg. $\mathrm{kg}^{-1}$ no T3 para 1,70 mg. kg-1 no T4. Embora não se tenha encontrado referências com esses tratamentos, há trabalhos (ARAÚJO et al., 2003; GINSING et al., 2004) que reportam que a biodegradação do glifosato é mais rápida do que a do AMPA, o que explicaria o fato de teores do herbicida serem relativamente baixos e não diferirem entre si no solo, enquanto o metabólito AMPA é significativamente superior quando se aumenta a quantidade de princípio ativo aplicado. De modo geral, é citado que a meia vida do glifosato é menor do que a do AMPA, o que explicaria a detecção e acúmulo de AMPA em solos com elevadas dosagens desse herbicida. Essa afirmativa é embasada no trabalho de Araújo et al. (2003), que verificaram maiores teores de AMPA nos solos nos quais houve aplicações sucessivas de glifosato.

Nos tratamentos com imazetapir, não houve diferenças significativas $(\mathrm{p} \leq 0,05)$ nos teores de resíduo desse herbicida no solo entre as parcelas cultivadas com soja $\mathrm{GM}_{\mathrm{RR}} \mathrm{T} 5$ $\left(0,54 \mathrm{mg} \cdot \mathrm{kg}^{-1}\right)$ e com a convencional T6 (0,60 mg. $\left.\mathrm{kg}^{-1}\right)$. Esse comportamento foi similar quando se avaliaram os grãos: foram detectados valores entre $0,12 \mathrm{mg} \cdot \mathrm{kg}^{-1}$ (T5) e $0,16 \mathrm{mg} \cdot \mathrm{kg}^{-1}$ (T6). Essas concentrações são superiores ao limite máximo permitido desse herbicida segundo normativa ANVISA que é de 0,10 mg. $\mathrm{kg}^{-1}$ (AGROFIT, 2007).

Ao se avaliarem os resíduos de glifosato nos grãos, foi verificado que há presença dessa molécula, proporcionalmente à dosagem aplicada. No tratamento em que se realizou uma aplicação de glifosato (T3), a concentração foi de $19 \mathrm{mg} \cdot \mathrm{kg}^{-1}$, enquanto que, naquele em que foram realizadas duas aplicações (T4), a concentração aumentou para $36 \mathrm{mg} \cdot \mathrm{kg}^{-1}$. Esses resultados são preocupantes, uma vez que o limite máximo estabelecido pela ANVISA é de $10 \mathrm{mg} \cdot \mathrm{kg}^{-1}$ (AGROFIT, 2007). Ao monitoraremse as concentrações de AMPA, o comportamento foi similar, ou seja, em soja tratada uma vez com glifosato, o resíduo foi de 9 mg. $\mathrm{kg}^{-1}$ (T3) e nas parcelas tratadas duas vezes, foram detectados 12 mg.kg-1 (T4). Duke et al. (2003) detectaram menores valores de resíduos de glifosato nos grãos (2,18 e 3,08 mg. $\left.\mathrm{kg}^{-1}\right)$, mas os de AMPA foram elevados (7,27 e 25,00 mg. $\left.\mathrm{kg}^{-1}\right)$ em grãos de soja $\mathrm{GM}_{\mathrm{RR}}$ tratada com o herbicida na dosagem de $1260 \mathrm{~g}$ ia ha ${ }^{-1}$, aplicado 8 semanas após o plantio (56 dias). As causas dos menores teores de resíduo de glifosato nesses grãos (DUKE et al., 2003), embora a dosagem tenha sido superior (1260 $\left.\mathrm{g}_{\text {ia ha }}{ }^{-1}\right)$ à empregada neste trabalho (960 $\mathrm{g}$ ia ha $\left.{ }^{-1}\right)$, não foram demonstradas, mas é conhecido que a metabolização da molécula na planta é dependente, além do genótipo, das condições edafoclimáticas durante o cultivo, podendo ser essas condições as causas das diferenças.

Os maiores teores de isofavonas totais foram detectados em grãos de soja $\mathrm{GM}_{\mathrm{RR}}$ tratada com imazetapir (T5), em média 19\% superiores aos da cultivar convencional com o mesmo tratamento (T6). Não houve diferenças significativas $(p \leq 0,05)$ entre os demais tratamentos com a cultivar $\mathrm{GM}_{\mathrm{RR}}$ (Tabela 3). Os maiores teores de isoflavonas no T5 podem estar relacionados com a maior competição das plantas desse tratamento, devido à maior presença da cobertura vegetal no tratamento com imazetapir, no

Tabela 2. Resíduos de glifosato, imazetapir e AMPA no solo e nos grãos.

\begin{tabular}{|c|c|c|c|c|c|c|}
\hline \multirow[t]{2}{*}{ Tratamento } & \multicolumn{3}{|c|}{ Solo } & \multicolumn{3}{|c|}{ Grãos } \\
\hline & $\begin{array}{l}\text { Glifosato } \\
\left(\mathrm{mg}^{2} \mathrm{~kg}^{-1}\right)\end{array}$ & $\begin{array}{c}\text { Imazetapir } \\
\left(\mathrm{mg}^{2} \mathrm{~kg}^{-1}\right)\end{array}$ & $\begin{array}{c}\text { AMPA } \\
\left(\mathrm{mg}^{\mathrm{k}} \mathrm{kg}^{-1}\right)\end{array}$ & $\begin{array}{l}\text { Glifosato } \\
\left(\mathrm{mg}^{2} \mathrm{~kg}^{-1}\right)\end{array}$ & $\begin{array}{c}\text { Imazetapir } \\
\left(\mathrm{mg} \cdot \mathrm{kg}^{-1}\right)\end{array}$ & $\begin{array}{c}\text { AMPA } \\
\left(\mathrm{mg}^{2} \mathrm{~kg}^{-1}\right)\end{array}$ \\
\hline T1 - BRS 244RR capina & n.d. & n.d. & n.d. & n.d. & n.d. & n.d. \\
\hline T2 - BRS 154 capina & n.d. & n.d. & n.d. & n.d. & n.d. & n.d. \\
\hline T3 - BRS 244RR 1x glifosato & 0,40 & n.d. & $1,03^{\mathrm{b}}$ & $19^{\mathrm{b}}$ & n.d. & 9 \\
\hline T4 - BRS 244RR 2x glifosato & 0,30 & n.d. & $1,70^{\mathrm{a}}$ & $36^{\mathrm{a}}$ & n.d. & 12 \\
\hline T5 - BRS 244RR 1x imazetapir & n.d. & 0,54 & n.d. & n.d. & 0,12 & n.d. \\
\hline T6 - BRS 154 1x imazetapir & n.d. & 0,60 & n.d. & n.d. & 0,16 & n.d. \\
\hline
\end{tabular}

n.d. - não detectado. Médias, na mesma coluna, com letras iguais não apresentam diferença significativa $(\mathrm{p}<0,05)$. 
Tabela 3. Teores totais de isoflavonas dos grãos de soja submetidos aos diferentes tratamentos, expressos em agliconas.

\begin{tabular}{lc}
\hline \multicolumn{1}{c}{ Tratamentos } & Isoflavonas (mg.100 $0^{-1} \mathrm{~g}$ b.u.) \\
\hline T1 - BRS 244RR capina & $196 \pm 9^{\mathrm{abc}}$ \\
T2 - BRS 154 capina & $177 \pm 8^{\mathrm{c}}$ \\
T3 - BRS 244RR 1x glifosato & $193 \pm 28^{\mathrm{abc}}$ \\
T4 - BRS 244RR 2x glifosato & $225 \pm 4^{\mathrm{ab}}$ \\
T5 - BRS 244RR 1x imazetapir & $231 \pm 14^{\mathrm{a}}$ \\
T6 - BRS 154 1x imazetapir & $187 \pm 9^{\mathrm{bc}}$ \\
\hline
\end{tabular}

Médias, na mesma coluna, com letras iguais não apresentam diferença significativa $(\mathrm{p}<0,05)$.

qual foi observada menor eficiência (dados não apresentados) no controle de plantas daninhas, quando comparado às demais formas de manejo.

Os teores de isoflavonas variaram de 177 a $231 \mathrm{mg} .100 \mathrm{~g}^{-1}$, sendo os teores médios de $211 \mathrm{mg} .100 \mathrm{~g}^{-1}$ e $182 \mathrm{mg} .100 \mathrm{~g}^{-1}$ para a cultivar $\mathrm{GM}_{\mathrm{RR}}$ e não modificada, respectivamente. Esses valores situam-se dentro dos parâmetros comumente citados na literatura (GENOVESE et al., 2005; WANG et al., 2000; CARRÃO-PANIZZI et al., 2003). É fato, entretanto, que há significativa variação de concentração de isoflavonas em soja, em função de genótipos, regiões e condições de cultivo. Genovese et al. (2005), por exemplo, avaliaram catorze variedades de soja não modificada fornecidas pela Embrapa no ano de 2003, produzidas em Ponta Grossa (Paraná, Brasil), e as concentrações variaram de $57 \mathrm{mg} .100 \mathrm{~g}^{-1}$ a $188 \mathrm{mg} .100 \mathrm{~g}^{-1}$. Em genótipos cultivados nos EUA, Wang et al. (2000) reportaram valores de $116 \mathrm{mg} .100 \mathrm{~g}^{-1}$ a $274 \mathrm{mg} .100 \mathrm{~g}^{-1}$. Duke et al. (2003) observaram

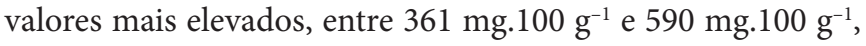
em outros genótipos.

Ao se compararem os teores médios de isoflavonas de soja $\mathrm{GM}_{\mathrm{RR}}\left(211,2 \mathrm{mg} \cdot 100 \mathrm{~g}^{-1}\right)$ e não modificada (182,2 mg. $\left.100 \mathrm{~g}^{-1}\right)$, foi verificado que a transformação genética não afetou essa variável de forma significativa $(\mathrm{p} \leq 0,05)$, o que também foi observado por Taylor et al. (1999). De modo similar, Mccann et al. (2005) verificaram que os teores médios e variações de isoflavonas entre 25 variedades de soja $\mathrm{GM}_{\mathrm{RR}}$ e 25 variedades não modificadas obtidas da Monsanto nas safras de 2000, 2001 e 2002 foram similares dentro de cada safra, mas variando entre safras.

Alguns autores como Padgette et al. (1995), Duke et al. (2003) e McCann et al. (2005) afirmam que as variações encontradas nos teores de isoflavonas estão mais relacionadas com o genótipo, tipo de solo, temperatura ou outras condições adversas no cultivo do que ao fato de ter-se alterado a resistência do herbicida glifosato. Neste trabalho, isso também foi observado. As sementes provenientes da Embrapa Trigo de Passo Fundo, utilizadas neste experimento, apresentaram, em média, $141( \pm 9) \mathrm{mg} .100 \mathrm{~g}^{-1}$ para a cultivar $\mathrm{GM}_{\mathrm{RR}} \mathrm{e}$ $123( \pm 1) \mathrm{mg} .100 \mathrm{~g}^{-1}$ para a não modificada. Ao se cultivar esse material na Região Sul do RS, em Planossolo, os teores médios passaram para $211 \mathrm{mg} .100 \mathrm{~g}^{-1}$ e $182 \mathrm{mg} .100 \mathrm{~g}^{-1}$ para soja $\mathrm{GM}_{\mathrm{RR}}$ e não modificada, respectivamente. Isso pode ser conseqüência das variações mais acentuadas de temperatura e de umidade na região de Planossolo, do que na região de Latossolo Vermelho Distrófico típico de Passo Fundo. As isoflavonas constituem-se em metabólitos secundários indicadores de respostas a estresses bióticos e abióticos, sugerindo-se, com isso, que adversidades edafoclimáticas durante o cultivo podem induzir à maior síntese e acúmulo desses compostos nos grãos.

Médias, na mesma coluna, com letras iguais não apresentam diferença significativa $(\mathrm{p}<0,05)$.

O perfil das isoflavonas presentes nas duas variedades de soja submetidas aos diferentes tratamentos é apresentado na Tabela 4 e mostra que a maioria $(98,3-99,5 \%)$ se encontra na forma glicosilada na semente. A ausência de acetilglicosídeos está justificada uma vez que sua formação está associada a processamentos envolvendo calor seco, como a tostagem e a extrusão da farinha de soja (COWARD et al., 1998). Por outro lado, a formação de agliconas resulta da atuação das $\beta$-glicosidases endógenas, como, por exemplo, quando a soja é deixada de molho ou mesmo durante armazenamento prolongado em condições de alta umidade relativa (MATSUURA et al., 1989; LEE et al., 2003). Isso explica a baixa porcentagem presente nas sementes, cuja formação foi provavelmente decorrente do processo de moagem e extração da soja para a análise. As pequenas diferenças observadas entre as porcentagens de malonilglicosídeos e $\beta$-glicosídeos não parecem relacionadas aos tratamentos aplicados, e seriam atribuídas à baixa estabilidade térmica dos malonilglicosídeos, que através de desesterificação formam facilmente os $\beta$-glicosídeos.

Em relação à distribuição das isoflavonas (Tabela 5), diferenças significativas foram encontradas entre as variedades BRS 244 RR e BRS 154, tratadas ou não, principalmente no que concerne à menor porcentagem de daidzeína e maior de genisteína total da BRS 154 em relação à BRS 244 RR. Novamente, a aplicação ou não de herbicidas não resultou em diferenças nesses parâmetros avaliados, exceto por uma tendência a um aumento de daidzeína com conseqüente diminuição de genisteína total na BRS 244 RR submetida a duas aplicações de glifosato. As variações encontradas nas porcentagens são similares às relatadas para as variedades da Embrapa, safra 2003 (GENOVESE et al., 2005).

\section{Conclusões}

A aplicação de glifosato em pós-emergência, no controle de plantas daninhas durante o cultivo de soja $\mathrm{GM}_{\mathrm{RR}}$ BRS $244 \mathrm{RR}$, em áreas de Planossolo, resulta em resíduos dessa molécula nos grãos, ultrapassando o limite máximo permitido pela legislação brasileira, bem como a presença de resíduos de AMPA no solo e nos grãos. Há uma tendência do teor e do perfil das isoflavonas não serem afetados nem pela aplicação de glifosato, nem pela transformação genética, havendo necessidade de estudos mais aprofundados.

\section{Agradecimentos}

À Embrapa Trigo, de Passo Fundo-RS, pelo fornecimento das sementes de soja; à FAPERGS, pelo financiamento (Proade 3, 05/2234-4) à pesquisa e pela bolsa de IC; ao PROAP/CAPES, pelo apoio financeiro; à SESU-MEC, pela bolsa PET; e ao Centro Agropecuário da Palma, pelo apoio na instalação do experimento. 
Tabela 4. Perfil de isoflavonas dos grãos de soja submetidos aos diferentes tratamentos.

\begin{tabular}{llccc}
\hline \multicolumn{1}{c}{ Tratamentos } & \multicolumn{3}{c}{$\%$} \\
\cline { 2 - 5 } & $\beta$-glicosídeos & Malonilglicosídeos & Acetilglicosídeos & Agliconas \\
\hline T1 - BRS 244 RR capina & $15,1 \pm 1,0^{\mathrm{ab}}$ & $84,4 \pm 1,0^{\mathrm{bc}}$ & n.d. & $0,6 \pm 0,0^{\mathrm{c}}$ \\
T2 - BRS 154 capina & $11,9 \pm 1,1^{\mathrm{c}}$ & $87,5 \pm 1,2^{\mathrm{a}}$ & n.d. & $0,5 \pm 0,1^{\mathrm{c}}$ \\
T3 - BRS 244 RR 1x glifosato & $12,5 \pm 1,6^{\mathrm{bc}}$ & $86,8 \pm 1,8^{\mathrm{ab}}$ & n.d. & $0,7 \pm 0,2^{\mathrm{bc}}$ \\
T4 - BRS 244 RR 2x glifosato & $17,4 \pm 2,4^{\mathrm{a}}$ & $81,9 \pm 2,5^{\mathrm{c}}$ & n.d. & $0,8 \pm 0,1^{\mathrm{b}}$ \\
T5 - BRS 244 RR 1x imazetapir & $12,5 \pm 0,3^{\mathrm{c}}$ & $86,0 \pm 0,4^{\mathrm{a}}$ & n.d. & $1,5 \pm 0,2^{\mathrm{a}}$ \\
T6 - BRS 154 1x imazetapir & $17,3 \pm 1,2^{\mathrm{a}}$ & $81,0 \pm 1,2^{\mathrm{c}}$ & n.d. & $1,7 \pm 0,2^{\mathrm{a}}$ \\
\hline
\end{tabular}

n.d. não detectados. Médias, na mesma coluna, com letras iguais não apresentam diferença significativa $(\mathrm{p}<0,05)$.

Tabela 5. Distribuição das formas totais de isoflavonas presentes nos grãos de soja submetidos aos diferentes tratamentos.

\begin{tabular}{|c|c|c|c|}
\hline \multirow[t]{2}{*}{ Tratamentos } & \multicolumn{3}{|c|}{$\%$ total $^{*}$} \\
\hline & Daidzeína & Gliciteína & Genisteína \\
\hline T1 - BRS 244RR capina & $46,0 \pm 0,7^{b}$ & $5,6 \pm 0,2^{\mathrm{a}}$ & $48,4 \pm 0,6^{\mathrm{b}}$ \\
\hline T2 - BRS 154 capina & $41,2 \pm 0,5^{c}$ & $4,5 \pm 0,3^{\mathrm{b}}$ & $54,2 \pm 0,7^{\mathrm{a}}$ \\
\hline T3 - BRS 244RR 1x glifosato & $47,7 \pm 1,8^{\mathrm{ab}}$ & $5,8 \pm 0,1^{\mathrm{a}}$ & $46,5 \pm 1,9^{\mathrm{bc}}$ \\
\hline T4 - BRS 244RR 2x glifosato & $49,7 \pm 0,2^{\mathrm{a}}$ & $5,9 \pm 0,1^{\mathrm{a}}$ & $44,4 \pm 0,1^{c}$ \\
\hline T5 - BRS 244RR 1x imazetapir & $46,1 \pm 0,4^{\mathrm{b}}$ & $5,9 \pm 0,2^{\mathrm{a}}$ & $48,0 \pm 0,4^{\mathrm{b}}$ \\
\hline T6 - BRS 154 1x imazetapir & $39,8 \pm 0,3^{c}$ & $5,3 \pm 0,4^{\mathrm{a}}$ & $54,9 \pm 0,6^{\mathrm{a}}$ \\
\hline
\end{tabular}

${ }^{*}$ A porcentagem total de cada aglicona representa a soma das formas livres e conjugadas presentes, expressas como agliconas. Médias, na mesma coluna, com letras iguais não apresentam diferença significativa $(\mathrm{p}<0,05)$.

\section{Referências bibliográficas}

AGROFIT. Sistema de Agrotóxicos Fitossanitários. Disponível em: $<$ http://www.agrofit.com.br>. Acesso em: jan. 2007.

ANVISA - Agência Nacional de Vigilância Sanitária. Disponível em: <http://www.anvisa.gov.br>. Acesso em: 14 fev. 2007.

ARAÚJO, A. S. F.; MONTEIRO, R. T. R.; ABARKELI, R. B. Effect of glyphosate on the microbial activity of two Brazilian soils. Chemosphere, v. 52, n. 5, p. 799-804, 2003.

BUSSE, M. D. et al. Glyphosate toxicity and the effects of long-term vegetation control and soil on soil microbial communities. Soil Biology and Biochemistry, v. 33, p. 1777-1789, 2001.

CARRÃO-PANIZZI, M. C.; SIMÃO, A. S.; KIKUCH, A. Efeitos de genótipos, ambientes e de tratamentos hidrotérmicos.na concentração de isoflavonas agliconas em grãos de soja. Pesquisa Agropecuária Brasileira, v. 38, n. 8, p. 897-902, 2003.

COWARD, L. et al. Chemical modification of isoflavones in soyfoods during cooking and processing. American Journal of Clinical Nutrition, v. 68, p. 1486S-1491S, 1998.

DUKE, S. O. et al. Isoflavone, glyphosate, and aminomethylphosphonic acid levels in seeds of glyphosate-treated, glyphosate-resistant soybean. Journal of Agricultural and Food Chemistry, v. 51, n. 1, p. 340-344, 2003.

ELMORE, R. W. et al. Glyphosate-resistant soybean cultivar response to glyphosato. Agronomy Journal, v. 93, p. 404-407, 2001.

EMBRAPA. Sistema Brasileiro de Classificação de Solos. 2 ed. Brasília: Embrapa Produção de informação; Rio de Janeiro: Embrapa Solos, 2006. 306 p.

GENOVESE, M. I.; LAJOLO, F. M. Determinação de isoflavonas em derivados de soja. Ciência e Tecnologia de Alimentos, v. 21, n. 1, p. 86-93, 2001

GENOVESE, M. I.; HASSIMOTTO, N. M. A.; LAJOLO, F. M. Isoflavone Profile and Antioxidant Activity of Brazilian Soybean Varieties. Food Science and Technology International, v. 11, n. 3, p. 205-211, 2005.

GIMSING, A. L. et al. Chemical and microbiological soil characteristics controlling glyphosate mineralization in Danish surface soils. Applied Soil Ecology, v. 27, n. 3, p. 233-242, 2004.
ISAAA - International Service for the Acquisition of Agri-biotech Applications. Global Status of Commercialized Biotech/GM Crops: 2006. Disponível em: <http://www.isaaa.org/Resources/ Publications/briefs/35/executivesummary/default.html $>$. Acesso em: 15 maio 2007.

LEE, S. J. et al. Variation in Isoflavone of Soybean Cultivars with Location and Storage Duration. Journal of Agricultural and Food Chemistry, v. 51, n. 11, p. 3382-3389, 2003.

MATSUURA, M.; OBATA, A.; FUKUSHIMA, D. Objectionable flavor of soy milk developed during the soaking of soybeans and its control. Journal of Food Science, v. 54, n. 3, p. 602-605, 1989.

MCCANN, M. C. et al. Glyphosate-Tolerant Soybeans Remain Compositionally Equivalent to Conventional Soybeans (Glycine max L.) during Three Years of Field Testing. Journal of Agricultural and Food Chemistry, v. 53, n. 13, p. 5331-5335, 2005.

PADGETTE, S. R. et al. Development, identification, and characterization of a glyphosate-tolerant soybean line. Crop Science, v. 35, p. 1451-1461, 1995.

REDDY,K. N.; RIMANDO, A. M.; DUKE, S. O. Aminomethylphosphonic acid, a metabolite of glyphosate, causes injury in glyphosate-treated, glyphosate-resistant soybean. Journal of Agricultural and Food Chemistry, Columbus, v. 52, n. 16, p. 5139-5143, 2004.

SONG, T. et al. Soy isoflavone analysis: quality control and a new internal standard. American Journal of Clinical Nutrition, v. 68, p. 1474S-1479S, 1998.

TAYLOR, N. B. et al. Compositional analysis of glyphosate-tolerant soybeans treated with glyphosate. Journal of Agricultural and Food Chemistry, v. 47, n. 10, p. 4469-4473, 1999.

VEIGA, F. et al. Dynamics of glyphosate and aminomethylphosphonic acid in a forest soil in Galicia, north-west Spain. The Science of the Total Environment, v. 271, n. 1-3, p. 135-144, 2001.

WANG, C. et al. Isoflavone content among maturity group 0 to II soybeans. Journal of the American Oil Chemists' Society, v. 77, n. 5 , p. $483-487,2000$. 